\title{
Complex patterns of shotgun injuries in a Suicide Pact; a Case Report
}

\author{
KM Tikiri Bandara Gunathilake ${ }^{1^{*}}$, Muditha Vidanapathirana ${ }^{2}$ \\ ${ }^{1}$ Office of the Judicial Medical Officer, Base Hospital, Awissawella, Sri Lanka, \\ ${ }^{2}$ Depratment of Forensic Medicine, Faculty of Medical Sciences, University of Sri Jayewardenepura, Sri Lanka
}

\begin{abstract}
If firearm injuries involve more than one individual with unknown circumstance, it attracts the interest of the public, media and the law, especially regarding the manner of death. A suicide pact is an agreement between two or more people to commit suicide together at a given place and time. Following discussion is based on two dead bodies; a male and a female found dead with firearm injuries with unknown circumstances with complicated atypical firearm injuries. A male and a female were found dead. They were lovers in their young age and were not allowed to get married. However, both had conflicts in their marriages and they developed an extramarital affair among them for a one-year duration. Father witnessed the male committing suicide with a firearm holding with one hand and triggering using a stick and falling on the dead body of a female. Female had contact 12 bore shotgun injury with a cartridge containing buckshot pellets. Seven exited with shored exits. Of them, 6 recovered from the clothes and the scene and the remaining $8 \times 8 \mathrm{~mm}$ buckshot pellet recovered from the male. The male had two injuries on the abdomen; one contact 12 bore shotgun injury with $2 \times 2 \mathrm{~mm}$ birdshot pellets and another superficial non-fatal injury with a buckshot pellet. The first firearm shot was reconstructed and explained by a unique position of the victims; Male leaning behind the female. The accessibility to the trigger could have been achieved by using a stick. Finally, this was a failed suicide pact, ended up as a dyadic death.
\end{abstract}

Keywords: Abdomen, male, female, suicide pact, Shotgun, buckshot pellets,

Received: 27 April 2019, Revised version accepted: 20 June 2019, Published: 30 June 2018. *Corresponding author: Gunathilake KMTB, \Email: Tikirii__bandara@yahoo.com, (D) https://orcid.org/0000-0002-8485-4550

Cite this article as: Gunathilake KMTB, Vidanapathirana M. Complex patterns of shotgun injuries in a Suicide Pact; a Case Report. Medico-Legal Journal of Sri Lanka, 2019;7(1): 26-31. DOI: http://doi.org/10.4038/mljsl.v7i1.7391

Copyright: @ 2019 with the Medico-legal Journal of Sri Lanka.

This is an open-access article distributed under the terms of the Creative Commons Attribution 4.0 International License, which permits unrestricted use, distribution and reproduction in any medium provided the original author and source are credited.

\section{Introduction}

Sri Lanka is a country with the highest suicidal rates and in 2018 , it ranked number $29^{\text {th }}$ in the world. ${ }^{[1]}$ Suicides by firearms are not uncommon in military camps.

Homicide is killing a person by another man. ${ }^{[2]}$ Sometimes, homicide followed by suicide and are common in family conflicts.

Firearm injuries could be a homicide, suicide or accident. ${ }^{[3]}$ When involves more than one individuals with unknown circumstance, it attracts the interest of the public, media and the criminal justice system regarding the interpretation of the injuries and the reconstruction of the event. In the absence of independent eyewitnesses, complex injury patterns may cause problems in the reconstruction and interpretation. However, it is the duty of the forensic pathologist to reconstruct the incident based on the facts available at the scene and the postmortem examination.

In a suicide pact, two or more individuals agree and plan to commit suicide. ${ }^{[4]}$ Suicide pacts are common among married or romantic partners. Whereas, a dyadic death refers to an incident where homicide is followed by the perpetrator's suicide. ${ }^{[5]}$

Following case discussion is based on two dead bodies; a male and a female found dead with firearm injuries with the unknown circumstance with complicated atypical firearm injuries.

\section{Case report}

A male and a female were found dead. They had a love affair in their young age and were not allowed to get married. Then they individually got married to different partners and were living in the same village with their children. However, both had conflicts in 
their marriages and they developed an extramarital affair among them for a one-year duration.

A day before the incident, the male person left his family and went to his father's place. Next day, the female also left to meet him. At around $3.45 \mathrm{pm}$, father of the male person heard the sound of a firearm and rushed to the place. Father had seen a body of a female lying on the ground and his son was standing with a shotgun in his hand. As he reached the scene, son shot himself on his abdomen and had fallen on top of the female body.

Scene visit was done in the next day. The scene was situated inside a jungle and the two bodies were found in the middle of a gravel road. The male body was lying on top of the female. There were a 12 bore shotgun and a buckshot empty cartridge at the scene (Fig. 01).

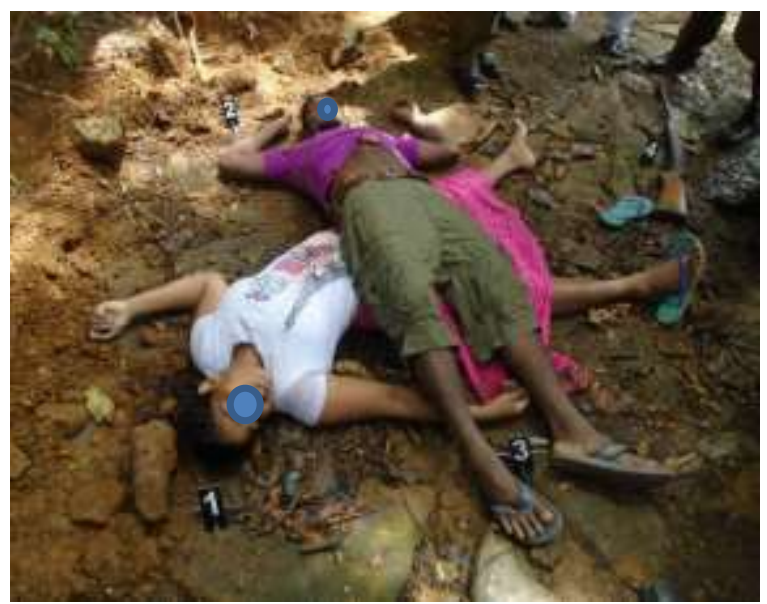

Figure 01: (1) The female body, (2) Male body, (3) 12 bore buckshot empty cartridge case, (4) 12 bore shotgun

At the scene, the father of the male demonstrated how the male victim shot himself while holding the muzzle end with the left hand and triggered the shotgun by a stick in right hand (Fig. 02).

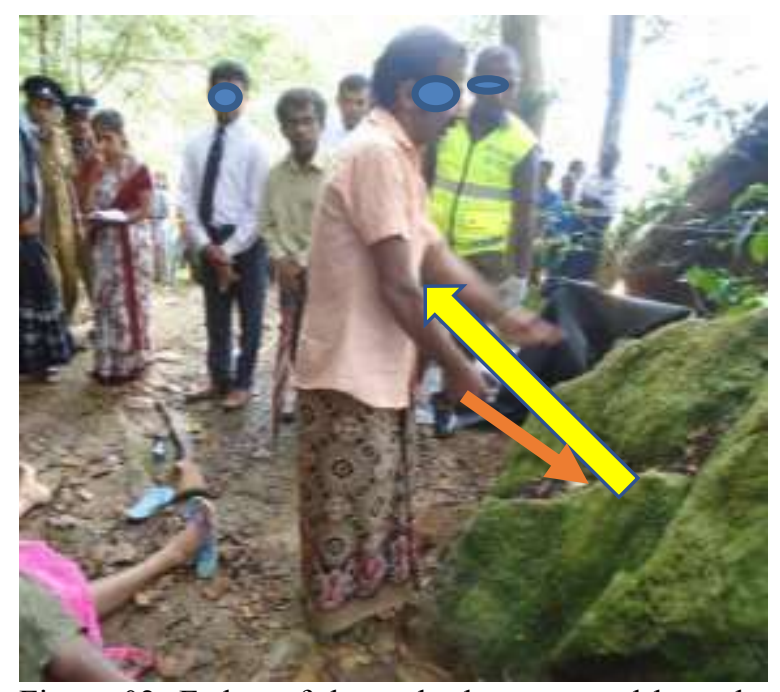

Figure 02: Father of the male demonstrated how the victim shot himself. The yellow arrow shows how he held the gun and the orange arrow shows the stick and how he pushed the trigger.

The bodies were not subjected to X-rays due to nonavailability of the facilities. The autopsy revealed that the age of the female and the male were 26 and 25 respectively. Their clothing was not disturbed. Male was clad in a purple T-shirt, white banyan and a brown quarter-trouser.

The male person's purple coloured T-shirt was stained with blood and had 2 perforations. The larger, $3.5 \mathrm{x}$ $2.5 \mathrm{~cm}$ perforation was found along the midline, $30 \mathrm{~cm}$ from the shoulder. The margins were burnt and blackened. The other perforation was $0.75 \times 0.75 \mathrm{~cm}$, situated $5 \mathrm{~cm}$ right from the midline and $30 \mathrm{~cm}$ from the shoulder. The margins were not burnt (Fig. 03).

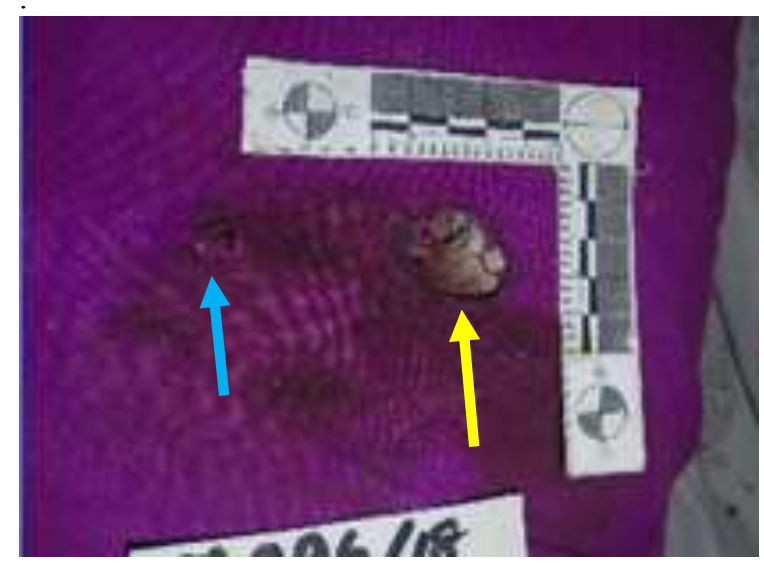

Figure 03: Oval shaped larger defect with burnt and blackened edges (Yellow arrow) and another $0.75 \times 0.75 \mathrm{~cm}$ circular smaller defect (blue arrow) in the T-shirt of the male. 
Underlying white coloured banyan of the male person was bloodstained and had two almost similar sized and shaped perforations with similar appearances (Fig. 04)

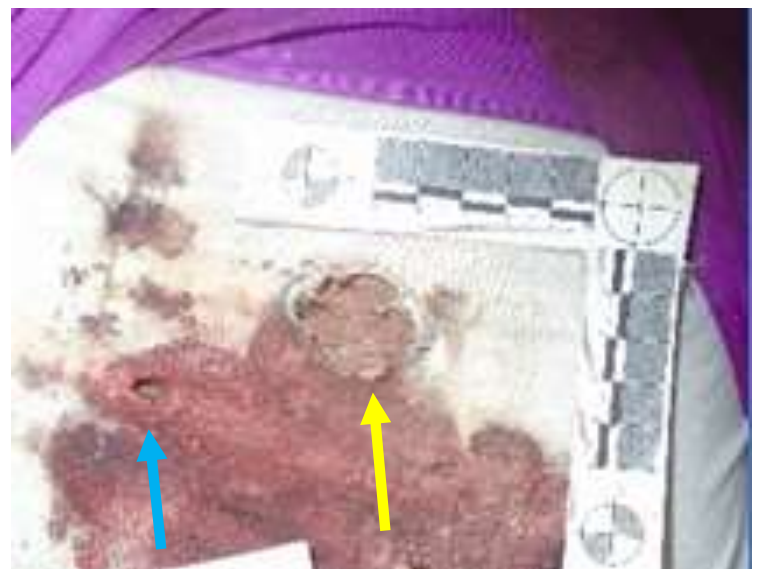

Figure 04: two perforations one larger (Yellow arrow) and one smaller (Blue arrow) in the blood-stained banyan of the male.

The underlying body of the male had a circular perforated laceration, $2.5 \times 2.5 \mathrm{~cm}$, in the mid-third of the abdomen, along the midline, $2 \mathrm{~cm}$ above the umbilicus. Edges were blackened and burnt. A patterned imprint abrasion, $0.25 \mathrm{~cm}$ thick was found around the wound (Fig. 05). A wad was recovered inside the body (Fig. 06). There were multiple (more than 50) $2 \times 2 \mathrm{~mm}$ size metal balls inside the body (Fig. $06)$. There were no exit wounds.

Another perforated laceration, $0.75 \times 0.75 \mathrm{~cm}$, on the right upper third of the abdomen, $5 \mathrm{~cm}$ above the umbilicus and $4 \mathrm{~cm}$ right from the midline. Margins were abraded. The upper edge of the wound was undercut (Fig. 05). The tract was $1.5 \mathrm{~cm}$ deep and an $8 \times 8 \mathrm{~mm}$ size deformed metal ball was recovered from the base of the tract (Fig. 07). There was no other injury on the male body.

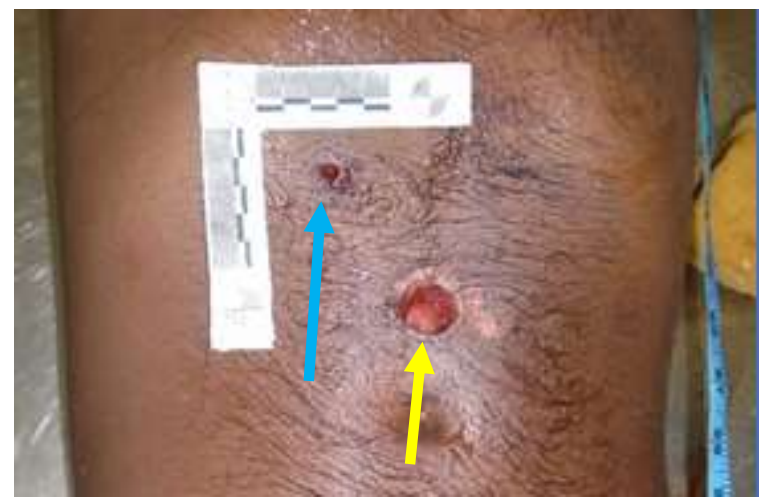

Figure 05: Contact firearm entry wound (Yellow arrow) and a pellet entry wound (blue arrow) of the male.

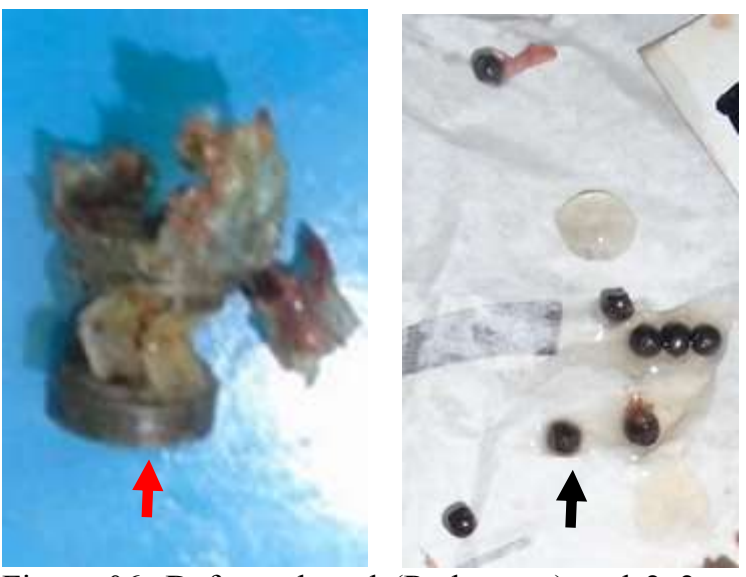

Figure 06: Deformed wad (Red arrow) and $2 \times 2 \mathrm{~mm}$ birdshot pellets (Black arrow) recovered from the male.

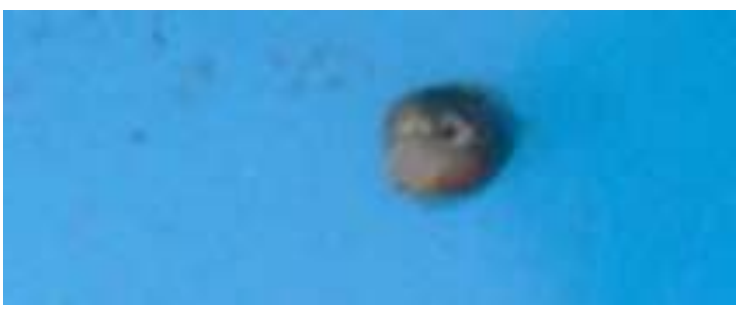

Figure 07: 12 bore buckshot pellet $(8 \times 8 \mathrm{~mm})$ recovered from the male

In the autopsy of the female body, the T-shirt of the female, had a roughly circular perforation, $2.5 \times 2 \mathrm{~cm}$, on the front left side, $5 \mathrm{~cm}$ from the midline and $35 \mathrm{~cm}$ from the shoulder. Edges were burnt and blackened (Fig. 08).

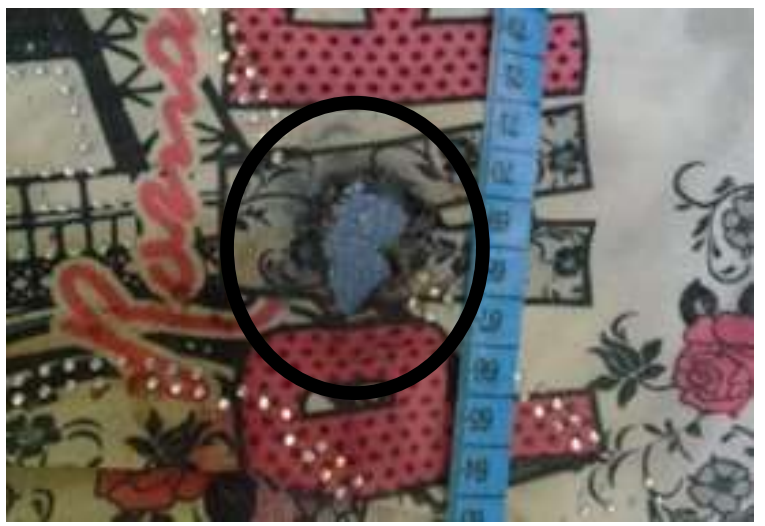

Figure $08 \mathrm{~T}$-shirt of the female had a large perforation with burnt and blackened margin.

Underlying banyan of the female was blood-stained and had similar roughly circular perforation with burnt and blackened margins (Fig. 09). 


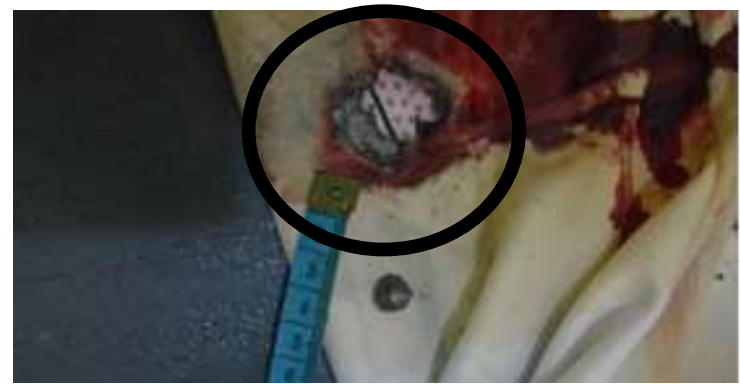

Figure 09: Perforation with burnt and blackened margins in the banyan of the female.

The underlying body of the female had an oval-shaped perforated laceration, $3 \times 2 \mathrm{~cm}$, on the right mid third of the abdomen, the centre of the injury was $3 \mathrm{~cm}$ from the midline and $4 \mathrm{~cm}$ above the umbilicus. Edges were blackened. A patterned imprint abrasion, $0.5 \mathrm{~cm}$ thick was found around the wound (Fig. 10). Wad was recovered inside the body. Two $8 \times 8 \mathrm{~mm}$ metal balls were recovered from the abdomen.

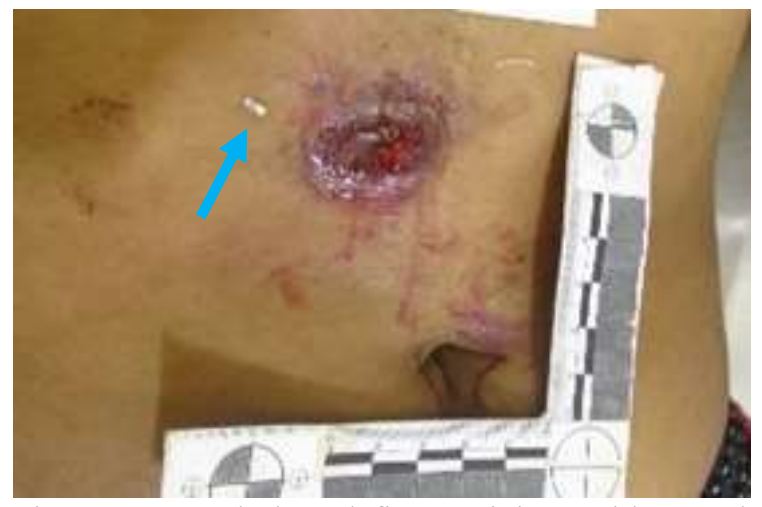

Figure 10: Oval shaped firearm injury with muzzle imprint of the female. (Blue arrow shows an artefact, a silver piece separated from her T-shirt)

There were 7 perforated lacerations, $0.75 \times 0.75 \mathrm{~cm}$ to $0.5 \times 0.5 \mathrm{~cm}$ in size, dispersed over a $6 \times 12 \mathrm{~cm}$ area on the right lower and mid-thirds of the loin. Margins had irregular abrasions (Fig. 11). Six $8 \times 8 \mathrm{~mm}$ pellets were recovered trapped in the clothes and the scene. Another $8 \times 8 \mathrm{~mm}$ pellet was recovered from the front abdominal wall of the male. Altogether, nine $8 \times 8 \mathrm{~mm}$ pellets were recovered. There were no other injuries on the female body.

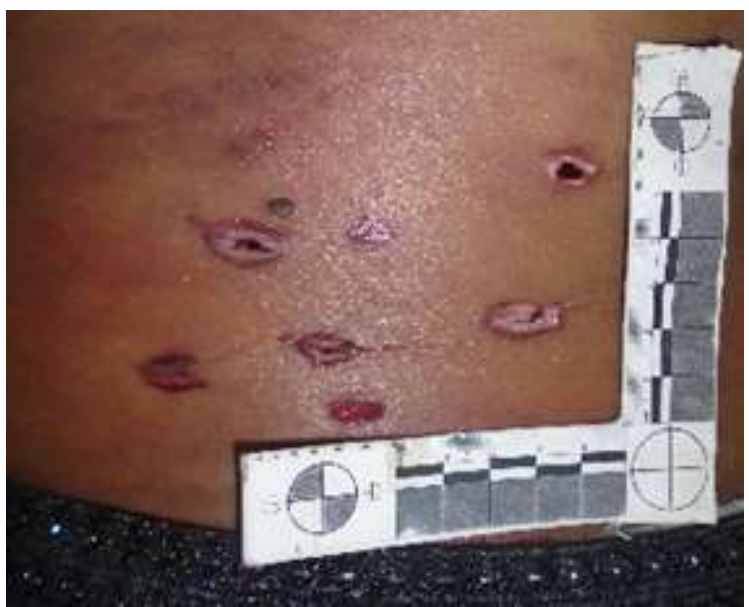

Figure 11: Shored exit wounds on the loin

The examination of the firearm revealed that there had been an empty birdshot cartridge trapped inside the gun.

\section{Discussion}

There are several types of love related deaths such as lust murders or overkilling. This circumstance seems to be completely different from those.

There are several interested parties involved in this case as there had been an extramarital affair among these two married individuals. Homicide due to anger or lust is not uncommon, however, once reconstructed, it was revealed that the main intent of both had been to commit suicide based on a love affair.

a study conducted from 2003 to 2010 at the Forensic Medicine Department of Tours (France), six cases were recorded as suicide pacts and the firearms were the preferred means of death. ${ }^{[6]}$

In close contact range, the clothes and the skin around the wound may be burnt. ${ }^{[7]}$ In this case, the female victim had $3 \times 2.5 \mathrm{~cm}$ perforation with burnt margin and a muzzle imprint. Therefore, the injury of the female should be a contact shotgun injury. It is compatible with the 12 bore shotgun available at the scene. Usually, the contact range shotgun wounds are much larger and destructive than the bullet injuries. ${ }^{[8]}$

In this case, two $8 \times 8 \mathrm{~mm}$ pellets recovered from the body and the exited 7 pellets recovered from clothes and the scene. The empty cartridge found at the scene was 12 bore SG. Therefore, pellets are compatible with 12 bore buckshot and compatible with 9 pellets of an SG cartridge. ${ }^{[3]}$ Therefore, in this case, the female had died with a 12 bore shotgun with an SG cartridge (Buckshot) in contact range. 
Regarding the death of the male, there was an independent eyewitness, the father of the victim. According to him, the male had shot himself once on his abdomen. But at the autopsy, there were two types of firearm injuries and two different types of pellets in the male.

The large wound, $2 \times 2 \mathrm{~cm}$ at the midline with muzzle imprint is compatible with a contact injury by the same 12 bore shotgun. However, more than 50 small $2 \times 2 \mathrm{~mm}$ pellets and a wad were recovered from the abdomen, and none had exited. This is compatible with 12 bore Birdshot cartridge pellets. ${ }^{[3]}$

The female had $8 \times 8 \mathrm{~mm}$ buckshot pellets. According to this circumstance, the female could be killed by another person with a buckshot fire. This is an isolated possibility and the real incident should be reconstructed considering all the circumstances. However, there were no other injuries on the female body to suggest threat or struggle and no scene or intelligence evidence of the involvement of a third person.

Further, the Male victim's injury pattern was much more complicated and atypical. Because, in addition to the birdshot fatal injury, there was another isolated firearm injury on the abdomen with an $8 \times 8 \mathrm{~mm}$ buckshot pellet, similar to the girl's pellets. This pellet also could be a pellet of the previous fire directed to the girl by another person! However, there was no evidence of a third party involvement at the scene.

Therefore, there is another explanation for this circumstance. The exit wounds found on the loin of the women had irregular abrasions and are compatible with shored exits. Therefore, she should have been lean to some surface. At the same time, the buckshot injury found on the abdomen of the male could be a reentry of the exited pellet from the back side of the female body. Therefore, he could have been behind the girl in the contact position.

Therefore, both could have decided to commit suicide together by firearm injury. Possibly, the male partner would have decided to commit suicide with a single, close contact firearm shot while leaning on the back side of the female. Then the other issue is the accessibility of the male to the trigger of the 12 bore shotgun in such a position! We propose that the male could have used the same witnessed mechanism that he used to commit suicide. Therefore, the male could have been holding the muzzle end of the 12 bore shotgun on the abdomen of the female with one hand and pushed the trigger using a stick in the other hand while leaning behind the female. The mechanism is depicted by Fig. 12. This proposed position is compatible with the injuries sustained by the victims; female had contact 12 bore shotgun injury with a cartridge containing $8 \times 8 \mathrm{~mm}$ size buckshot pellets. Two buckshot pellets were recovered from the female's abdomen. Seven $8 \times 8 \mathrm{~mm}$ buckshot pellets exited from the back with shored exits due to the leaning position of the male from behind. It was further confirmed by the recovery of six buckshot pellets from the clothes of the female and the scene and the remaining buckshot pellet from the anterior abdominal wall of the male. This pellet was recovered from the base of the shallow tract. This isolated injury did not show any blackening or burning and was compatible with the re-entry of the exited pellet from the backside of the female. Further, except for firearm injury, the female body did not have any evidence of threat or struggle.

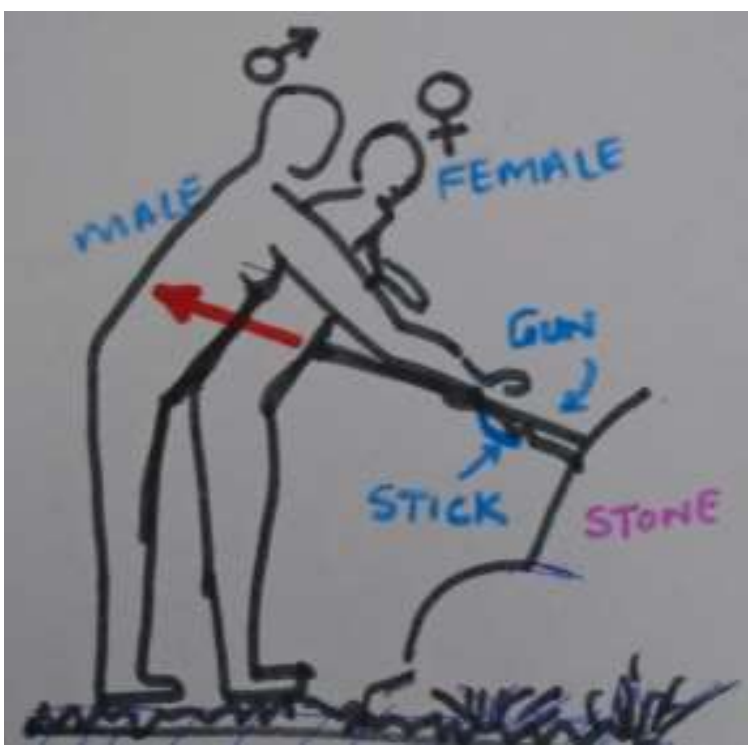

Figure 12: The possible reconstructed position of the victims of the first fire.

The female died but the male survived with this superficial penetration of a single buckshot pellet. Then, as witnessed by the father, the male committed suicide by shotgun injury on his abdomen with a 12 bore cartridge containing birdshot pellets.

Another issue is the reconstruction of the possible manners of these deaths. In a suicide pact, two or more individuals agree and plan to commit suicide. A suicide pact is an agreement between two or more people to commit suicide together at a given place and time. ${ }^{[6]}$ Suicide pacts are common among married or romantic partners, family members, or friends. In this case, the bodies only had injuries caused by firearm injuries and there was no evidence of threat or force. 
Therefore, it is clear that those victims needed to commit suicide with a single shot. Therefore, this is considered a failed suicide pact.

However, the male did not die with that attempt and committed suicide by using the same weapon with another type of cartridge containing birdshot pellets. Dyadic death refers to an incident where homicide is followed by the perpetrator's suicide. ${ }^{[8]}$ In this case, the girl was killed by the boy and then he had committed suicide. Therefore, now, this has become a dyadic death.

\section{Conclusions}

Meticulous scene investigations are important in suspicious deaths. Complicated cases of multiple deaths or cases with public and media interest must be handled by a team of experts.

In this case, both had fatal close contact shotgun injuries. One victim had fatal wounds with multiple exits by a 12 bore cartridge containing buckshot pellets and the other sustained two types of injuries; non-exited fatal 12 bore birdshot injury and a non-fatal superficial buckshot injury.

The event was reconstructed and explained by a unique position of the victims; boy leaning behind the girl. The accessibility to the trigger could have been achieved by using a stick. Finally, this was a failed suicide pact, ended up as a dyadic death.

\section{Disclosure statement}

Conflicts of interests: The authors declare that they have no conflicts of interests.
Funding: None

\section{References}

1. World population view. http:/ /worldpopulation review.com/countries/suicide-rate-by-country/

2. Reddy KSN; The essentials of forensic medicine and toxicology: $15^{\text {th }}$ Ed. India: Jaypee brothers; 1995. $\mathrm{p}-234$

3. Spitz WU, Spitz DJ, Clark R. Spitz and Fisher's Medicolegal Investigation of Death; $4^{\text {th }} \mathrm{Ed}$, Illinois: Charles Thomas; 2004.

4. Rajagopal S, Suicide pacts and the internet. BMJ. 2004 Dec 4; 329(7478): 1298-99. Doi: 10.1136/bmj.329.7478.1298

5. Berman AL Dyadic death: a typology. Suicide Life Threat Behav. 1996 Winter; 26(4):342-50. PMID: 9014263.

6. Prat S1, Rérolle C, Saint-Martin P. Suicide pacts: six cases and literature review. J Forensic Sci. 2013 Jul; 58(4):1092-8. Doi: 10.1111/15564029.12056 .

7. Knight's Forensic Pathology; Pekka sukko, Bernard Knight. $3^{\text {rd }}$ Ed; London: Arnold; 2004. p246.

8. JK Mason, Purdue BN; The Pathology of Trauma. $3^{\text {rd }}$ Ed; London: Arnold; 2000. p-65 